\title{
LA RESTAURACIÓN DEL ACLLAWASI EN EL SANTUARIO DE PACHACAMAC, 1940-1944. IDENTIFICANDO LAS HUELLAS DE VIOLLET-LE-DUC, UN ANÁLISIS COMPARATIVO ${ }^{(*)}$
}

\author{
THE RESTORATION OF THE ACLLAWASI IN THE SANCTUARY OF PACHACAMAC, 1940-1944. \\ IDENTIFYING THE TRACES OF VIOLLET-LE-DUC, A COMPARATIVE ANALYSIS \\ RODOLFO GERBERT ASENCIOS LINDO $0^{[\star]}$
}

Fecha de recepción: 12 de enero de 2017

Fecha de aprobación: 01 de febrero de 2017

\begin{abstract}
RESUMEN
La restauración del Acllawasi o Templo de las Mamaconas representa una de las primeras intervenciones a gran escala realizadas en el Santuario de Pachacamac, cuya importancia se debe no solo a que fue ejecutada por Julio C. Tello entre 1940 y 1944, sino a que dicho monumento es considerado uno de los edificios más representativos que conforman dicho santuario. Sin embargo, a pesar de su trascendencia, poco se conoce sobre los objetivos y fines que determinaron la restauración de esta edificación. Por ello, mediante la revisión de publicaciones, recortes periodísticos y documentos inéditos, el presente artículo esbozará el primer panorama sobre cómo se desarrolló dicha intervención, en la que además se evidencia la aplicación de los principios y postulados de Viollet-le-Duc, principal representante de la restauración estilística en Europa. Este análisis será un aporte que permita conocer acerca de la historia de la conservación arqueológica en el Perú.
\end{abstract}

\section{PALABRAS CLAVE}

Acllawasi, Pachacamac, Viollet-le-Duc

\section{ABSTRACT}

The restoration of the Acllawasi or Temple of the Mamaconas represents one of the first large-scale interventions carried out in the Sanctuary of Pachacamac. It owes its importance not only to the fact that Julio C. Tello executed it between 1940 and 1944, but also to the monument's importance among the buildings that make up the sanctuary. Nonetheless, despite its transcendence, little is known about the goals and ends that determined the restoration of this edifice. Thus, through an appraisal of publications, newspaper clippings, and unpublished documents, this paper sketches the first overview of the restoration process. It also illustrates the application, in the project, of the principles and proposals of Viollet-le-Duc, the main representative of European stylistic restoration. The analysis presented here will therefore allow readers to know about the history of archaeological conservation in Peru.

\section{KEYWORDS}

Acllawasi, Pachacamac, Viollet-le-Duc

${ }^{*}$ ) La primera exposición de este tema se realizó en el curso Seminario de Conservación, de la Maestría de Conservación del Patrimonio Edificado, de la Facultad de Arquitectura, Urbanismo y Artes de la Universidad Nacional de Ingeniería, en 2013. Seguidamente el autor profundizó su investigación como parte del desarrollo de su tesis de maestría.

(**) Arqueólogo por la Universidad Nacional Mayor de San Marcos, egresado de la maestría en Ciencias con mención en Conservación de Patrimonio Edificado de la Facultad de Arquitectura, Urbanismo y Artes de la Universidad Nacional de Ingeniería. Desarrolló la tesis inédita titulada Investigaciones De Las Shicras en el Sitio Precerámico de Cerro Lampay (2009). Codirector del proyecto Awqa Pacha, sobre el estudio de los sitios arqueológicos fortificados en los valles de Fortaleza, Pativilca y Huaura; y coautor de publicaciones científicas sobre los resultados del mismo. Actualmente se encuentra elaborando una tesis sobre la historia de la conservación arqueológica en el Perú, particularmente el caso del Templo del Sol, en el Santuario de Pachacamac. Contacto: gerbert.asencios@gmail.com 
devenir Vol. 4, N7, ENERO- JUNIO 2017, PP. 29-48 - ESTUDIOS I ISSN 2312-7562

UNIVERSIDAD NACIONAL DE INGENIERÍ, LIMA

\section{Ubicación del Santuario de Pachacamac}

El Santuario Arqueológico de Pachacamac se ubica en la costa central del Perú, en la provincia y departamento de Lima. Situado en la margen derecha del río Lurín, tiene un área de 465 hectáreas, de la cual un tercio alberga los importantes edificios. El santuario se asienta en los macizos rocosos que conforman una pequeña cadena de cerros bajos en su extremo sur, que a su vez marcan el límite de una extensa llanura arenosa conocida con el nombre Pampas de Atocongo. Así mismo, el límite oeste del sitio se encuentra a aproximadamente 600 metros al este de la línea de playa del océano Pacífico (Barrionuevo, 2007).

Figura 1. Plano del Santuario de Pachacamac

Fuente: Pachacamac GIS project: A practical application of geographic information systems and remote sensing techniques in andean archaeology (Tesis de maestría) (p. 55), por G. Matsumoto, 2005, Illinois: Southern Illinois University at Carbondale.

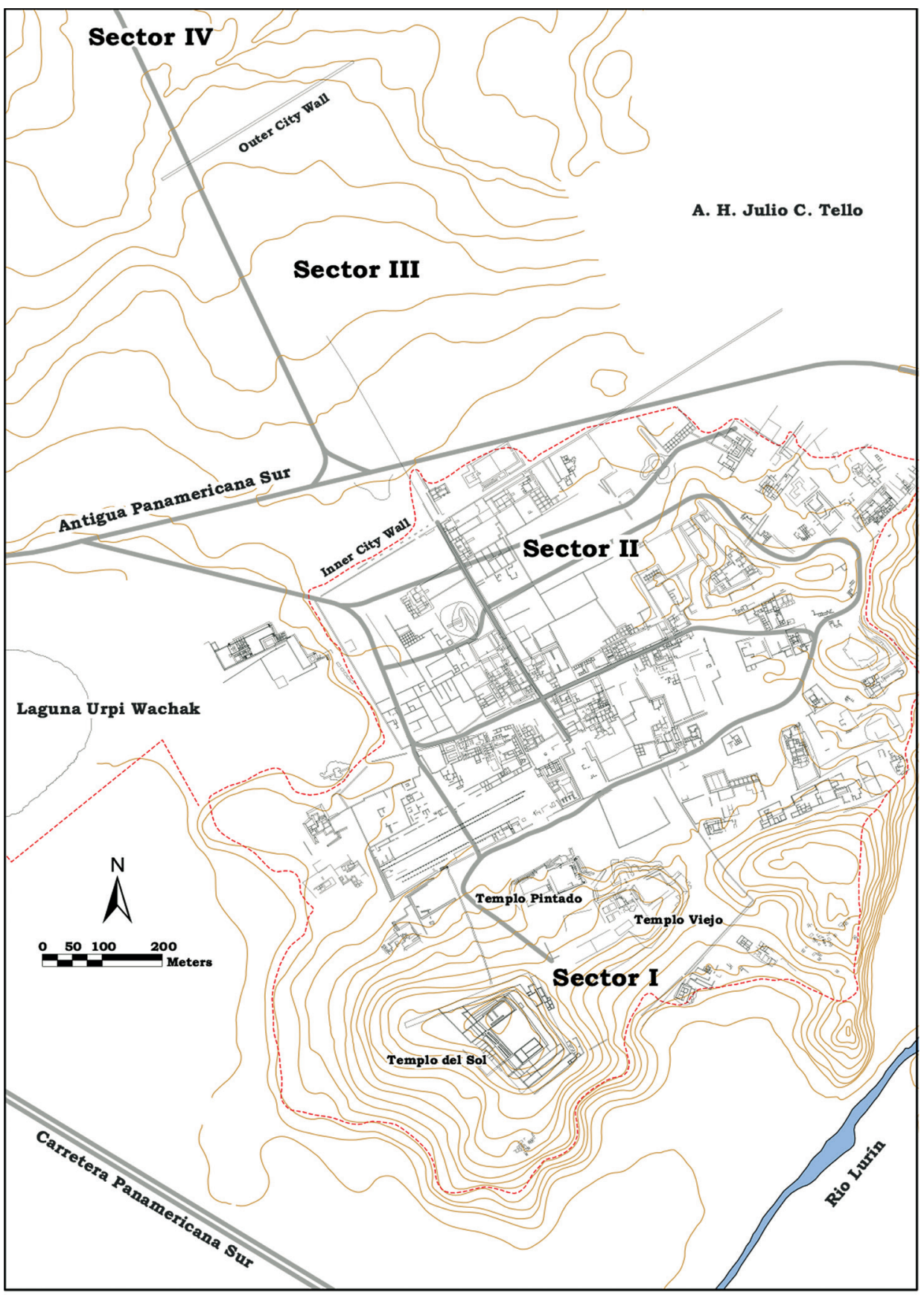




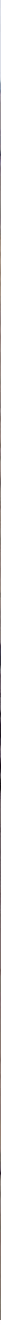

Julio C. Tello (2010) describe cuatro zonas dentro del santuario: donde están ubicados los templos al interior de la primera muralla -el Templo del Sol, el Templo Pintado, el Templo viejo de Pachacamac y el área de cementerios-; el área de los grandes aposentos o palacios cercados, dispuestos en la parte central, entre la primera y segunda muralla, además de los edificios al oeste del mismo, donde también se ubican los edificios conocidos como pirámides con rampa; la zona de los aposentos menores, aparentemente cercados, ubicados en el lado este del Santuario; y el área de los suburbios y residencias ubicados en el lado norte, delimitado por la tercera muralla. El Acllawasi se encuentra al oeste de la segunda muralla, en el lado noroeste, en la parte baja del santuario, donde se ubican los edificios Urpi Kocha y Urpi Wachak (Tello, 2010) (Figura 1).

Sobre el Acllawasi, Alberto Bueno (2012) afirma que su edificación fue posterior a la del Templo del Sol, y que cumplió la función de concentrar para su educación a las acllas, mujeres escogidas de diversas latitudes del imperio para cumplir las actividades de culto, servicios de los templos, o convertirse en las esposas de los principales nobles, del inca o del dios sol; otra función fue la de convertirse en productora de bienes preciados vinculados al culto y al estatus como telares, joyas, etc. (Figura 2).
Figura 2. Vista este-oeste del Acllawasi o Templo de las Mamaconas en la actualidad

Fuente: Fotografía por Rodolfo Gerbert Asencios Lindo, 2014. 


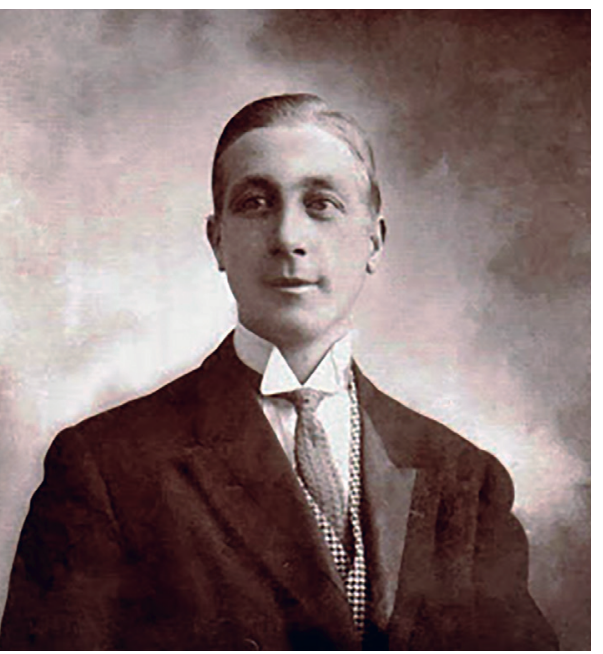

Figura 3. Albert Anthony Giesecke Parthymueller (1883-1968)

Fuente: Archivo Albert Giesecke, 2012

\section{El Acllawasi y las intervenciones realizadas entre 1938 y 1945}

Durante el gobierno de Oscar R. Benavides (1933-1939), Albert A. Giesecke Parthymueller intervino Pachacamac en 1938. Fue una de las primeras intervenciones de conservación en este santuario, que centró su atención en el Templo Pintado, el Templo del Sol y el Acllawasi. En este último se ejecutaron labores de limpieza; asimismo, se planteó un circuito para acceder a los principales edificios, el cual se acompañó de letreros con información sobre cada edificio (Rubio, 2007) (Figura 3).

Para las gestiones llevadas a cabo en torno a las labores de limpieza en el Acllawsi se tomó en cuenta la opinión de otros importantes intelectuales, como Luis E. Valcárcel, quien en una carta a Giesecke señala que "Otra cosa que conviene mucho es concentrar el trabajo en el retiro de escombros y las vías de acceso a cada uno de los tres grandes conjuntos: templo del sol, templo de Pachacamac y Mamacuna porque el tiempo avanza y preferible es que todo esto ya quede libre para ser visitado" (Comunicación personal, 20 de octubre de 1938. Archivo Giesecke). Asimismo, años después, Tello refiere una comunicación entre Albert Giesecke y Carlos Concha Cárdenas, en la cual se relatan detalladamente los resultados de su labor en el Acllawasi:

Las obras de limpieza en este Convento dieron como resultado el hallazgo de nuevos nichos, cuartos, puertas y gradas, muchas de ellas bajo varios metros de escombros. Se ha limpiado lo suficiente para demostrar que quedan bastantes construcciones por descubrir. Sin embargo, es enorme la cantidad de tierra que se ha movido durante la limpieza de este Convento. (Rubio, 2007, p. 122)

Durante el gobierno del presidente Manuel Prado y Ugarteche (1939-1944), Julio C. Tello inició sus labores de dirección de las investigaciones en Pachacamac, que incluyeron la intervención en distintos edificios del santuario: el Templo del Sol, Urpi Kocha y Urpi Wachak, la Plaza de los Peregrinos y el Acllawasi. Este último, es el edificio de mayor interés, pues presenta áreas y recintos compartimentados, así como muros con vanos de acceso y nichos trapezoidales en buen estado de conservación (Tello, 2012). Esta labor de intervención fue aprobada mediante Resolución Suprema del 27 de marzo de 1940, expedida por el Ministerio de Fomento y encomendada a Julio C. Tello, quién inició las actividades el 13 de mayo de 1940. El proceso comprendió tres etapas. Primero se llevaron a cabo trabajos de reconocimiento y exploración de prueba en el Templo del Sol, Templo del dios Pachacamac, Templo de Urpi Wachak, y Templo de la Luna o Mamacuna, de cuyos resultados preliminares se derivaron excavaciones de área. Luego se procedió a realizar excavaciones y descubrimientos, con el objetivo de visibilizar los principales monumentos reconocidos durante la fase previa, como el Templo de Urpi Wachak y los muros que rodean las cisternas. Finalmente, como último y más relevante paso, se procedió a la reconstrucción de la Mamacona (Tello, 2012) (Figura 4).

Las labores de excavación y restauración en el Acllawasi fueron registradas detalladamente y publicadas décadas después en la serie denominada Cuadernos de Investigación del Archivo Tello, específicamente en los números 6, 7 y 8, publicados en los años 2009, 2010 y 2012 respectivamente. La información allí reunida brinda importante información sobre los procedimientos ejecutados durante las labores de excavación y restauración, materia del presente artículo, que aquí se compararán con los principios establecidos por Viollet-le-Duc.

Durante este proceso, Tello contó con el apoyo de colegas y discípulos como Toribio Mejía Xesspe y Rebeca Carrión Cachot, así como de colaboradores de confianza como Cirilo Huapaya, José Cossi Salas y Julio Espejo, quienes dejaron un importante registro de campo, escrito y gráfico, que explica los procedimientos llevados a cabo. 

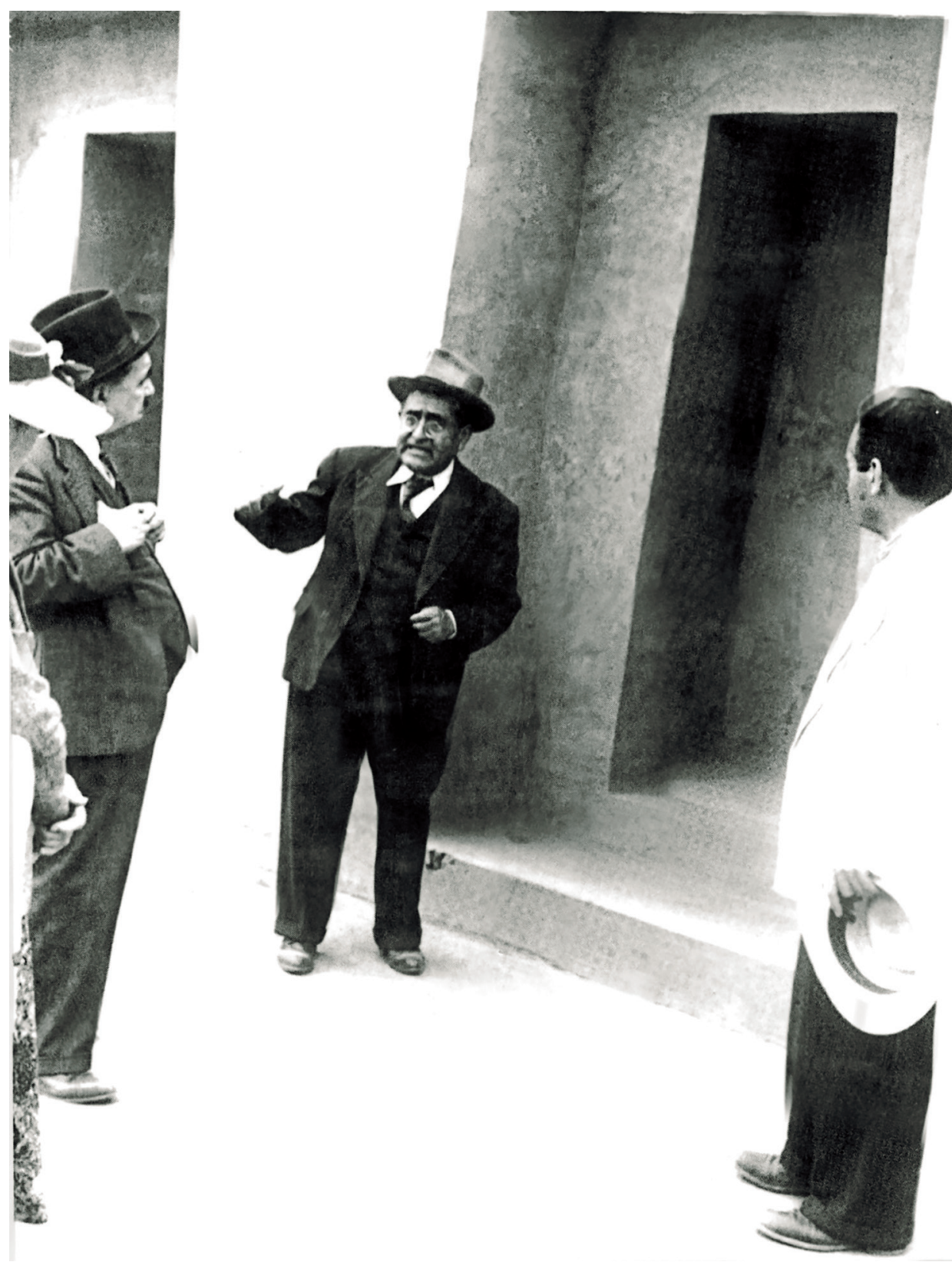

\section{Viollet-le-Duc y los principios del restauro científico}

En Europa, a mediados del siglo XIX, se instauró como disciplina científica la restauración; esta se erige entonces como una práctica profesional sistemática y consolidada, dotada de presupuestos teóricos propios y situada en un contexto en el que los Estados nacionales asumen como una responsabilidad social e institucional la restauración de su patrimonio cultural (Gonzáles-Varas, 2006).

En ese escenario, durante la primera mitad del siglo XIX, fue preponderante la restauración estilística, cuyo fundador y representante teórico fue Viollet-le-Duc (18141879), arquitecto francés que sentó las bases teóricas de una restauración desarrollada sobre los cimientos de la teoría de la Historia de Arte y de la Arquitectura, cuyo amplio
Figura 4. Julio C. Tello explicando a una delegación de visitantes sobre los trabajos de restauración en el Acllawasi

Fuente: Cuadernos de investigación del Archivo Tello: $N^{\circ}$ 8. Arqueología de Pachacamac: Restauración del Templo de la Luna (portada), por J. C. Tello, 2010, Lima, Perú: CEPREDIM - UNMSM. 


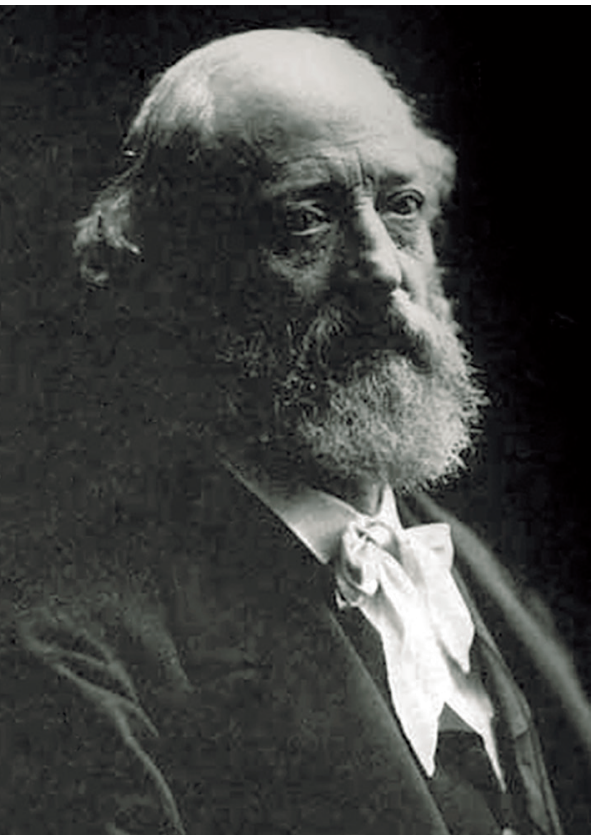

Figura 5. Viollet-le-Duc (1814-1879) representante de la restauración estilística en Europa

Fuente: Conservación de bienes culturales. Teoría, historia, principios y normas, (p. 158), por I. González-Varas, 2006, Madrid, España: Cátedra. espectro, en las décadas posteriores, marcó el camino de la conservación en Europa, principalmente en Italia y España. El sustento de esta propuesta de restauración eran las investigaciones históricas y arqueológicas, la obtención de datos mediante observaciones, y comparaciones de las obras de arte según la evolución de los estilos. Para Viollet-le-Duc la restauración tenía como objetivo recuperar por completo el bien cultural, y si este contaba con sus elementos perdidos y/o deteriorados estos podrían recuperarse bajo el análisis del razonamiento científico (Gonzáles-Varas, 2006) (Figura 5).

En 1866, Viollet-le-Duc publica su Diccionario Razonado de Arquitectura, en cuyo tomo VIII sintetiza lo expuesto hasta entonces sobre los principios de la restauración entendida como la unidad por estilo. Gonzáles-Varas (2006) lo resume en los siguientes principios rectores:

1. Toda actividad restaurativa debe sustentarse en un levantamiento planímetro y registro realizado de forma científica, respaldado con documentos e investigaciones arqueológicas. Pondera el uso de la fotografía, en tanto es un medio que permite obtener "apuntes inexcusables y documentos que se pueden consultar en todo momento..." (Wethered, 1875, p. 68). Así mismo, plantea que el especialista debe tener un detallado conocimiento de la época e historia del edificio que piensa intervenir, además de observar la singularidad de sus caracteres físicos, materiales, estructurales, y los aspectos históricos artísticos y culturales.

2. El restaurador debe contar con conocimientos sólidos sobre la importancia del perfil técnico de la restauración, pues la intervención no debe basarse solo en la apariencia del monumento, sino que debe extenderse hasta su estructura constructiva. Por lo tanto, debe de tener conocimiento pleno de los procedimientos técnicos y constructivos procedentes de diversas épocas de ocupación. Además de ello, como plantea Le-Duc, el restaurador debe conocer la eficiencia del empleo de materiales modernos que permita la duración de la intervención, cuyo uso es entonces válido.

3. El restaurador debe prestar atención a la funcionalidad del monumento; esto, para Viollet-le-Duc, no debe de descuidarse. Al respecto plantea que el mejor medio para conservar un edificio es otorgarle un uso que respete el edificio, y sea compatible con sus cualidades y el uso al que fue destinado originalmente.

4. Es crucial que el restaurador cuente con un alto grado crítico al adoptar actitudes frente a las modificaciones que se van a realizar en el edificio, así como las añadiduras, y/o transformaciones acontecidas en el monumento previamente, las cuales pueden desdecir de su valor real. No obstante, ello se deja al criterio del interventor: si bien por un lado las añadiduras pueden transgredir la unidad de estilo, por otro lado es necesario tomar en cuenta la especificidad de dichas añadiduras, si corresponden o pertenecen a la nueva unidad integral y estructural del edificio.

\section{Análisis comparativo de los postulados de Viollet-le-Duc y los trabajos de restauración en el Acllawasi}

Para llevar a cabo el análisis comparativo se emplearon los datos publicados en los Cuadernos del Archivo Tello, los cuales proporcionan notas, apuntes, gráficos y fotos de las acciones realizadas en el Acllawasi, las cuales se identificaron para luego compararlas con los postulados de Viollet-le-Duc.

1. Conocimiento pleno del edificio desde su registro planimétrico, documentos e historia del sitio.

Tello (2012) fue muy exhaustivo en el registro, lo cual exigió a sus colaboradores con la finalidad de "obtener datos preciosos" (p. 154) sobre los siguientes aspectos: los materiales, especialmente aquello relacionado con los adobes (medidas y composición) y 

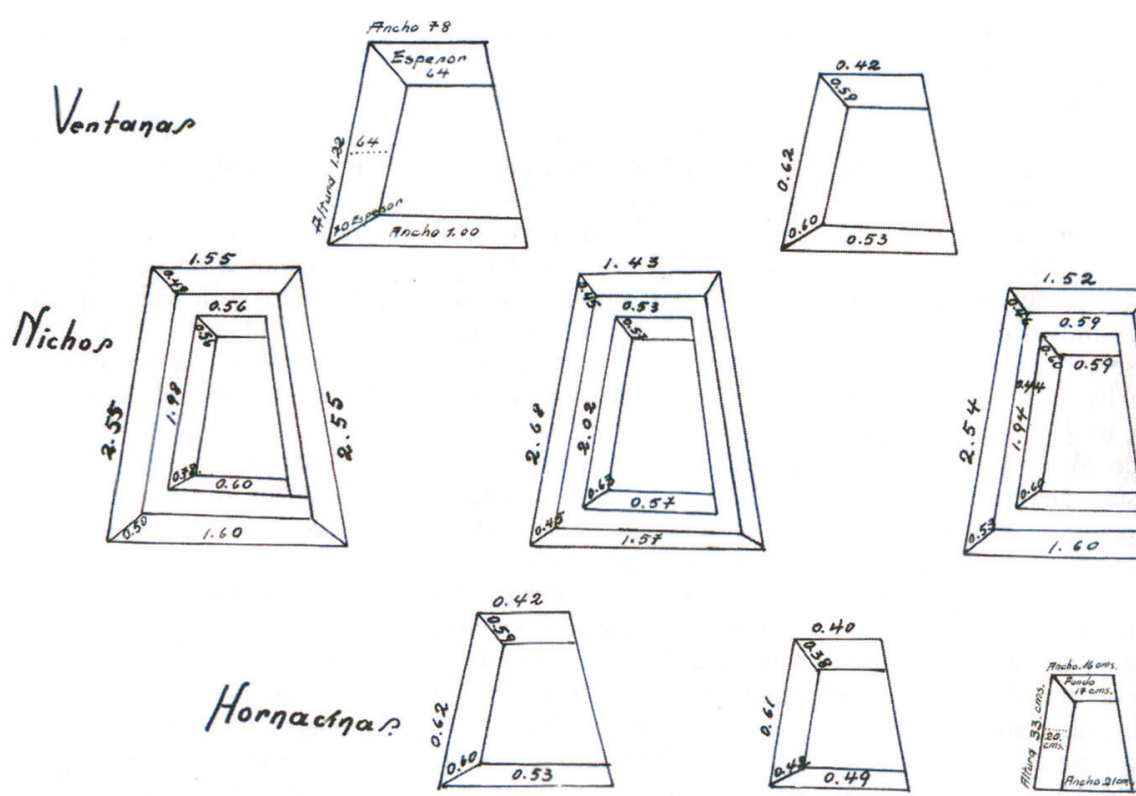

Figura 6. Registro gráfico de nichos y jambas con sus medidas tomadas para la restauración del Acllawasi o Templo de las Mamaconas

Fuente: Cuadernos de investigación del Archivo Tello: $N^{\circ}$ 10. Arqueología e Historia de Pachacamac (p. 160), por J. C. Tello, 2012, Lima, Perú: CEPREDIM UNMSM.

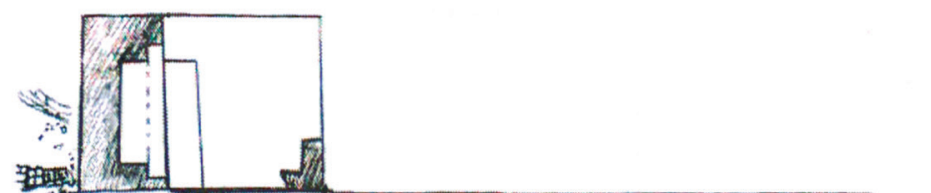

Figura 7. Registro en detalle de corte y en planta Norte-Sur del lado Este del Acllawasi realizado en 1942 durante su conservación

Fuente: Cuadernos de investigación del Archivo Tello: $N^{\circ}$ 8. Arqueología de Pachacamac: Restauración del Templo de la Luna (p. 39), por J. C. Tello, 2010, Lima, Perú: CEPREDIM - UNMSM.
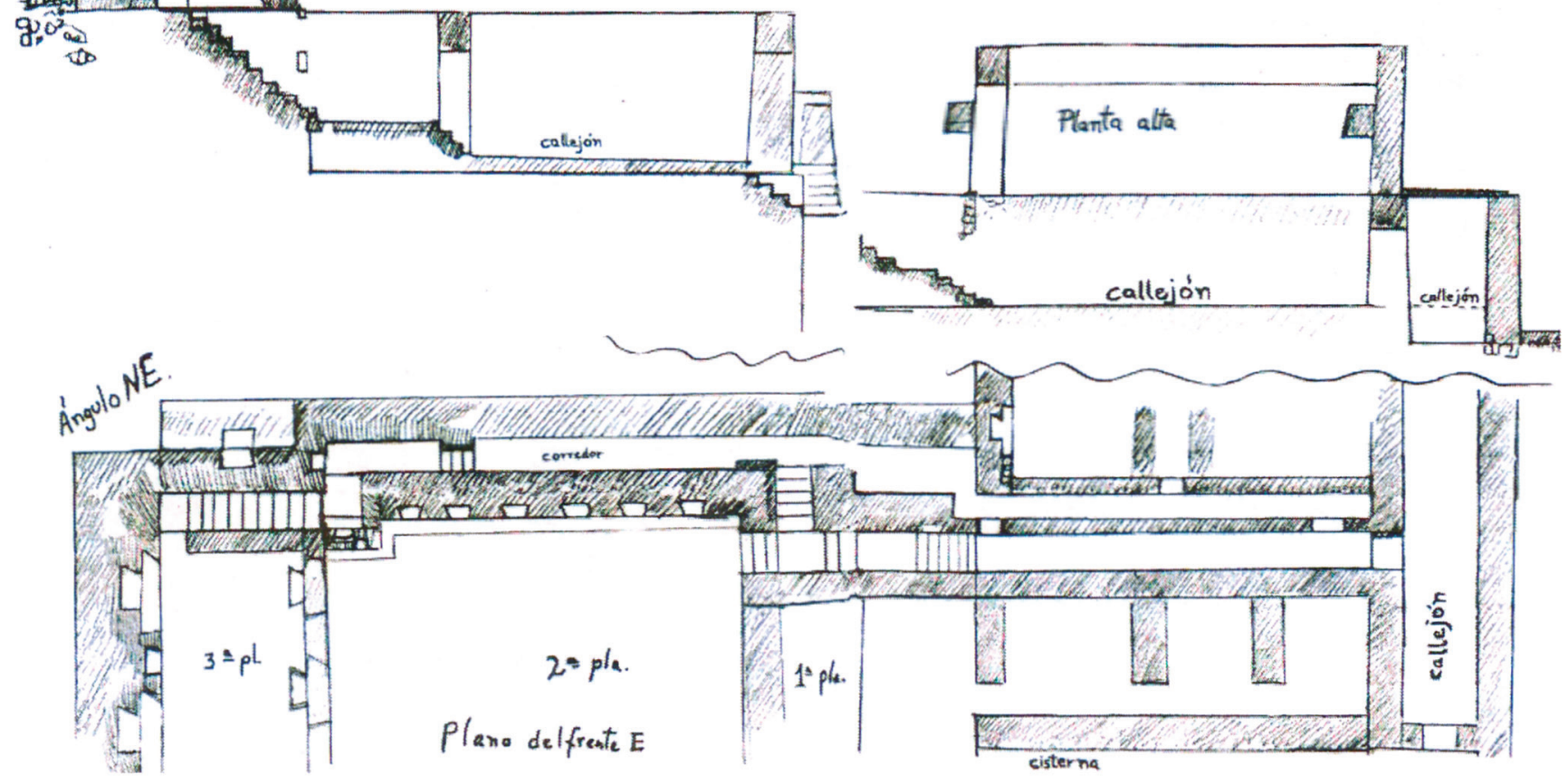


\section{Diaj2 ch Nore.}

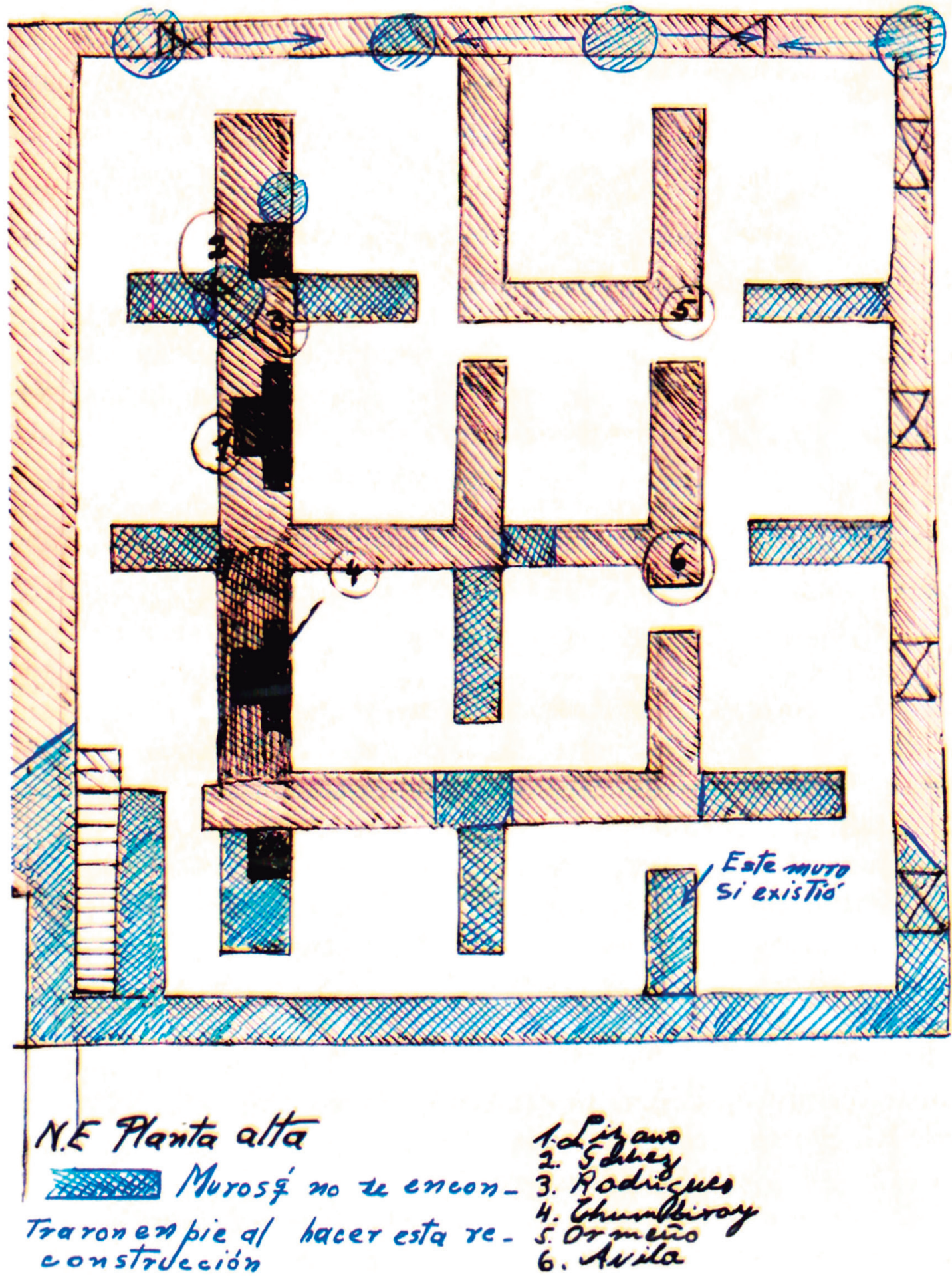

Figura 8. Registro planimétrico del Acllawasi de la parte noreste, planta alta, describiendo la ubicación del personal y los lugares donde no se encontraron en pie las estructuras durante su intervención

Fuente: Cuadernos de investigación del Archivo Tello: N²8. Arqueología de Pachacamac: Restauración del Templo de la Luna (p. 154), por J. C. Tello, 2010, Lima, Perú: UNMSM. 

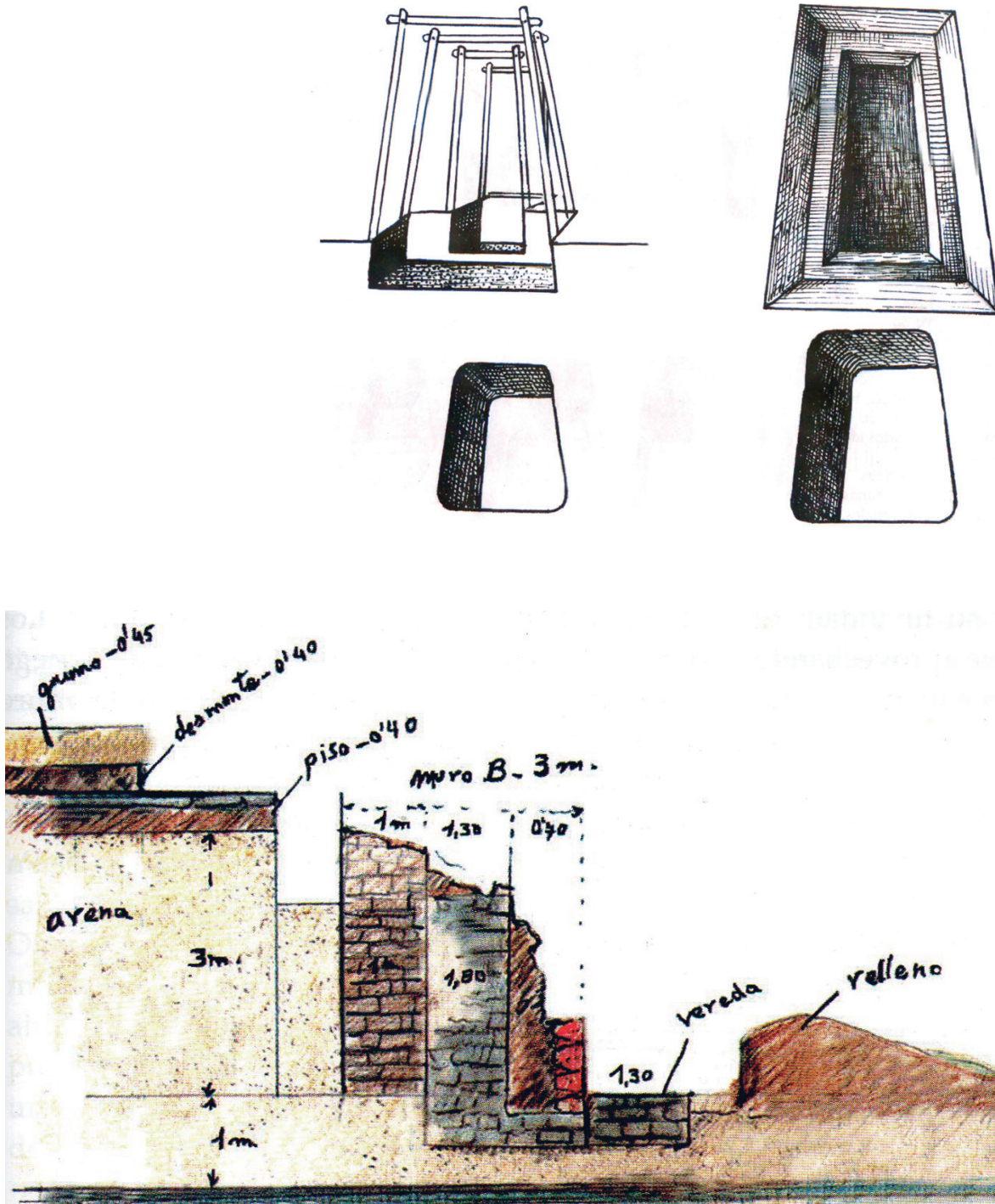

arena hímeda

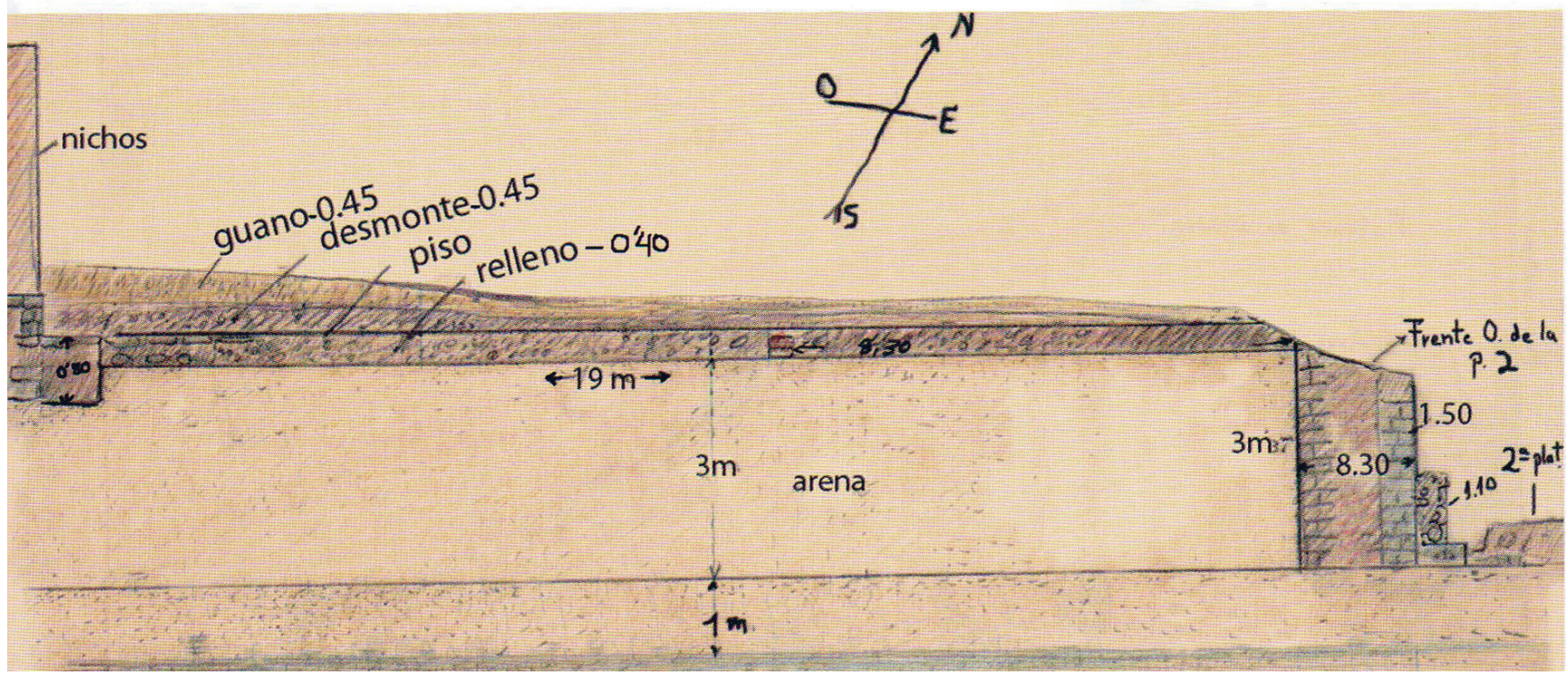

Figura 9. Registro del empleo del carrizo para la construcción de jambas y hornacinas en la intervención del Acllawasi

Fuente: Cuadernos de investigación del Archivo Tello: $N^{\circ}$ 10. Arqueología e Historia de Pachacamac (p. 160), por J. C. Tello, 2012, Lima, Perú: CEPREDIM UNMSM.

Figura 10. Elementos expuestos en las excavaciones. Imagen superior, registro de corte norte-sur de los elementos expuestos de la plataforma delante de los nichos. Imagen inferior, corte este-oeste del lado oeste de la poza $\mathrm{N}^{\circ} 2$, al pie de los nichos de las mamaconas Fuente: Cuadernos de investigación del Archivo Tello: $N^{\circ}$ 6. Arqueología de Pachacamac: Excavaciones en el Templo de la Luna y Cuarteles, 1940-1941 (p. 233), por J. C. Tello, 2009, Lima, Perú: CEPREDIM - UNMSM.

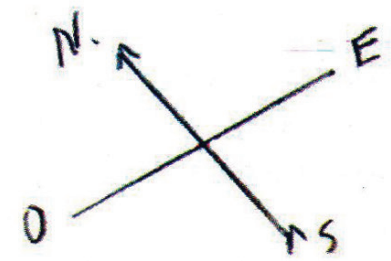
chacra 
devenir Vol. 4, N7, ENERO - JUNIO 2017, PP. 29-48 - EstudIOS I ISSN 2312-7562

UNIVERSIDAD NACIONAL DE INGENIERÍ, LIMA

Figura 11. Registro fotográfico del lado Este del Acllawasi

Fuente: Cuadernos de investigación del Archivo Tello: $N^{\circ}$ 8. Arqueología de Pachacamac: Restauración del Templo de la Luna (p. 115), por J. C. Tello, 2010, Lima, Perú: CEPREDIM - UNMSM. las piedras (tipos, proceso de obtención, proceso de talla y medidas); los materiales de relleno y construcción empleados en los pasadizos y enlucidos; la elaboración de los colores empleados y los materiales usados en techos, dinteles, troncos, sogas, petates etc. Cada dato contó con su respectivo registro gráfico. Toda esta información estuvo acompañada de planos y gráficos detallados. (Figuras 6,7 y 8 )

\section{Conocimiento pleno de los procedimientos técnicos y constructivos procedentes de} diversas épocas de ocupación

Las técnicas constructivas empleadas son otro de los aspectos relevantes que se investigaron para un mejor conocimiento del edificio, desde el tipo de suelo y la cimentación del mismo hasta la disposición de los muros y el relleno de estos. También se ahondó en la técnica utilizada para la construcción de los nichos y hornacinas, los cuales luego contaron con sus respectivas ilustraciones (Figuras 9 y 10 ).

La intervención en el Acllawasi también contó con registro fotográfico durante el proceso de las actividades de restauración, requisito exigido por Viollet-le-Duc: "No hay un solo detalle arquitectural que no tenga su inmediata comprobación en el mismo sitio que abone su autenticidad las fotografías de todo el proceso lo comprueban" (2012, p. 210) (Figuras 11 y 12).

Tello y sus colaboradores investigaron profusamente acerca de la historia del edificio, haciendo una revisión de documentación histórica como las crónicas de Estete, Cieza de León, Ávila, entre otros. Por otro lado, tomaron en cuenta las descripciones de los viajeros del siglo XVIII y XIX, como Tschudi y Rivero, Squier, Bastian, Hutchinson, Stevenson y Middendorf, para finalmente acudir al registro de Uhle, cuyas investigaciones fueron, para Tello, las primeras de tipo científico ejecutadas en el santuario. El equipo dirigido por Tello realizó investigaciones comparativas tomando como referencia edificios similares dentro del registro arquitectónico inca, que cumplieron la misma función en el amplio territorio del imperio, información que sería fundamental para entender mejor las labores de restauración. Como cita Rebeca Carrión (Tello, 2012),

Con este objeto, el Dr. Tello ha levantado un plano detalle del edificio y, en su actual viaje al Cusco, ha descubierto monumentos similares a este construidos de piedra que permitirá tener

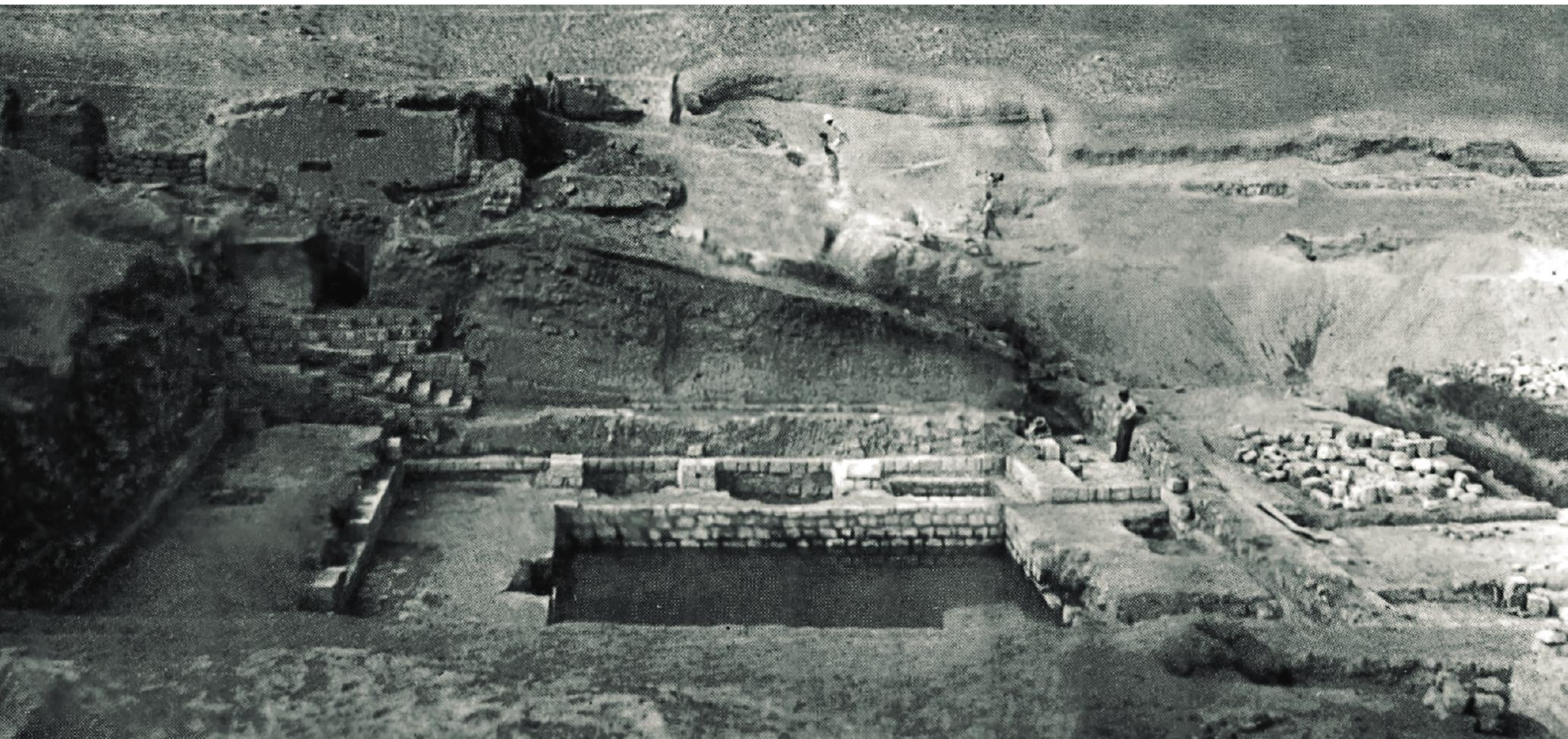


certeza de una reconstrucción adecuada de los techos, pisos y otros elementos integrantes arquitecturales, que en Pachacamac han desaparecido. (p. 164)

\section{Sobre la funcionalidad del edificio a restaurar}

En los cuadernos de investigación del archivo Tello, Rebeca Carrión menciona los objetivos a los que apuntaba la intervención en el Acllawasi:

De acuerdo con el propósito científico y turístico que inspiraron a la Junta Pro-Desocupados a auspiciar estos trabajos en las ruinas de Pachacamac (sic), el plan proyecto es el siguiente:

$1^{\circ}$ Presentar un parque arqueológico en el área comprendida en la herradura del algodonal, alrededor de la cual se encuentran tres monumentos importantes: el edifico de las Mamaconas oTemplo de la Luna en el extremo NO, el Templo de Urpi Wachak en el extremo SO; y el edificio con terrazas escalonadas en el centro de la herradura

$2^{\circ}$ Reconstruir totalmente el edificio de las Mamaconas por presentar casi completos sus principales compartimentos integrantes, y patios con cisternas.

(...)

$3^{\circ}$ Presentar un museo campestre como se ha hecho en algunas ruinas de México, exponiendo apropiadamente en los mismos edificios las muestras de cerámica, tejidos y otros implementos hallados en el proceso de excavaciones.

Lima, 29 de octubre de 1942. (Tello, 2012, p. 164)

Así mismo, Carrión Cachot (Tello, 2012), al remitir su informe, el cual detalla las labores realizadas en Pachacamac, comunica también la visita de los miembros de la Junta Pro-desocupados de Lima, y al respecto menciona lo siguiente:

El Sr. Alayza se interesó de tal manera en el asunto que no debe de paralizarse los trabajos en un instante hasta que quede terminado el proyecto de museo al aire libre.

(...)

Se ha entusiasmado mucho [Carlos Alayza] con lo que ha hecho en los pabellones de las Mamaconas que se; que va a botar una mayor cantidad de que tenía para la reconstrucción de
Figura 12. Registro fotográfico de intervención de las jambas

Fuente: Cuadernos de investigación del Archivo Tello: $N^{\circ}$ 8. Arqueología de Pachacamac: Restauración del Templo de la Luna (p. 52), por J. C. Tello, 2010, Lima, Perú: CEPREDIM - UNMSM.

Figura 13. Registro fotográfico del proceso de intervención

Fuente: Cuadernos de investigación del Archivo Tello: No 8. Arqueología de Pachacamac: Restauración del Templo de la Luna (p. 64), por J. C. Tello, 2010, Lima, Perú: CEPREDIM - UNMSM.

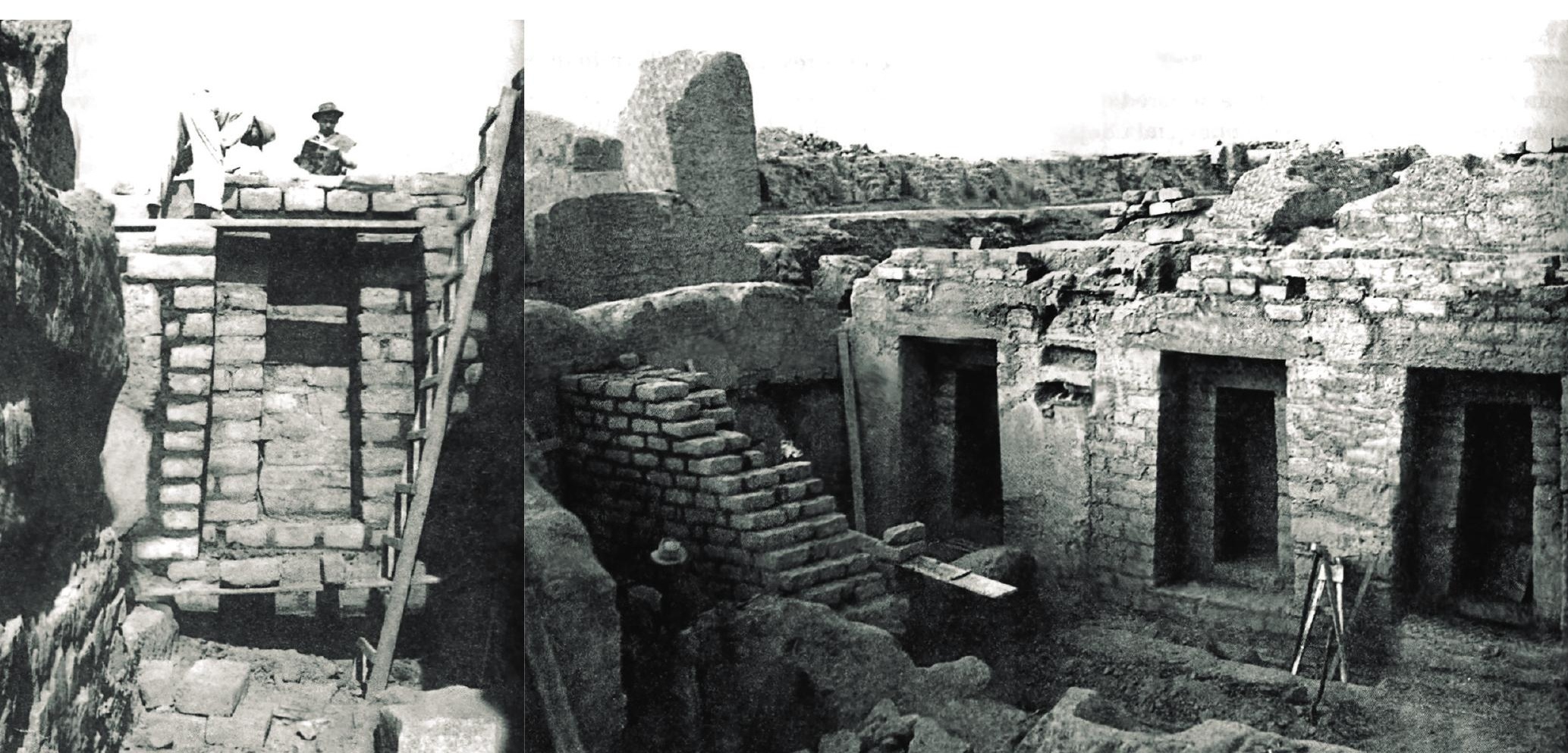


este monumento; que el museo planteado por usted será un hecho, y que por lo que va viendo, será algo digno de presentarlo en cualquier parte del mundo. (p. 165)

Años después, Tello (2012), en su memoria escrita en 1945, expuso la finalidad por la que el Gobierno otorgó la inversión para investigación y restauración en Pachacamac: “El gobierno del Perú ha auspiciado las investigaciones arqueológicas en Pachacamac y, en especial, la reconstrucción de uno de sus principales edificios, el Templo de Killay o de la Luna, destinado a ser la sede del futuro Museo de Pachacamac" (p. 37).

Así mismo, en la sección "Introducción" de la misma publicación, Tello al enumera los hallazgos y descubrimientos en Pachacamac: "...5 $5^{\circ}$ El descubrimiento total del Templo de la Luna [Acllawasi], y su reconstrucción. Este edificio está destinado a ser en el futuro la sede el Museo Arqueológico de Pachacamac" (2012, p. 44).

Finalmente, John Rowe (1946), tras la muerte de Tello en 1947, refiere sobre sus actividades de intervención en Pachacamac lo siguiente, afirmación que sería mencionada décadas después por Burger (2009):

Sus trabajos más recientes en el terreno fueron la limpieza del sitio incaico de Wiñay Wayna, cerca de Machu Picchu (1942) y la reconstrucción de la Mamacona en Pachacamac, ruina de las más imponentes de la ocupación incaica de la costa (1945-46). La Mamacona es, tal vez, el primer edificio antiguo del Perú reconstruido en gran escala. Tello pensaba instalar allí parte de su museo. (p. 292)

Así, Julio C. Tello asignó una función al edificio restaurado, que estaba orientada a integrar al visitante con los monumentos arqueológicos, acorde a su discurso nacionalista de apreciar la majestuosidad y fuerza creadora de la raza indígena (Figuras 14 y 15).

\section{Análisis crítico}

Tello (2012) precisa la no participación del arquitecto moderno en la reconstrucción del Acllawasi:

Para nada ha intervenido el arquitecto moderno; se ha trabajado de acuerdo a los principios de la ciencia arqueológica; se ha seguido el curso de los muros de la misma manera como se siguen dentro de una tonelada de fragmentos de alfarería, los fragmento de unidades distintas, y que son la base se una reconstrucción auténtica.

En los edificios del piso superior de Pachacamac se ha seguido el mismo procedimiento que se hizo para la reconstrucción de las grandes ánforas o tazas ceremoniales que yo recogiera en 1927 y que con tanto esfuerzo lograra reconstruirlo y ponerlo a sorpresa del público, como sucede con otros tantos testimonios admirables por su finura y belleza. (p. 210)

Sin embargo, la intervención no fue la aplicación de un recetario, sino la discusión y debate del proyecto y de distintos puntos de vista sobre la intervención. Para ello Tello contó con la participación externa de los miembros de la Junta Pro-desocupados de Lima, los arquitectos Rivero Tremouille y Emilio Harth Terré, colegas como Samuel Lotroph, y todo personaje que lo visitó durante el proceso de reconstrucción del Acllawasi. Rebeca Carrión Cachot escribe en 1942 en su informe sobre los trabajos realizados en Pachacamac (Tello 2012) al respecto:

El Sr. [Carlos] Alayza' considera indispensable que se restaure los techos de los pabellones puestos a la vista con sus propios palos de huarango que lo va hacer traer de Ica. Me pidieron que opinión sobre [Enrique] Rivero, Tremoulle [Tremouille] , [Emilio] Hart Terré, y les dije que me parecían muy buenos por que el primero lo acompañó a usted en un viaje por el Norte,

1. Miembro de la Junta Pro-desocupados de Lima. 


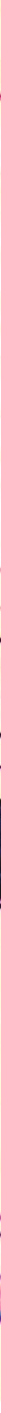

donde estudio algunos aspectos de la arquitectura Inka y pre-Inka: la fortaleza de Chankillo con sus techos de palo y huarango, etc. En 15 día tendremos una primera reunión con los especialistas. (p. 165)

Por otro lado, Tello (2012), en el proyecto del libro de Pachacamac que no pudo publicarse, menciona lo siguiente:

Luego, añadir los principios en que se apoya la reconstrucción [del Accllawasi]:

1) El cuidado de toda huella que ayude a conocer cómo era el edificio en conjunto y en los detalles. Los dinteles, las jambas, las entradas, las columnas, los nichos, los adobes de diferentes clases, la estructura de los muros de contención, etc.;

2) Las pruebas de tres o más etapas de reedificación que sufrió el primitivo edificio;

3) El cuidado de no agregar elemento alguno, por más insignificante que sea, fuera de las enseñanzas y exigencias derivadas del estudio cuidadoso de los escombros, del espesor de los muros y el curso que siguen, de los materiales de construcción, etc.;
Figura 14. Boceto del proyecto final del Accllawsi elaborado por Cirilo Huapaya en 1943

Fuente: Cuadernos de investigación del Archivo Tello: $N^{\circ} 8$. Arqueología de Pachacamac: Restauración del Templo de la Luna (p. 115), por J. C. Tello, 2010, Lima, Perú: CEPREDIM - UNMSM. 
devenir Vol. 4, N7, ENERO- JUNIO 2017, PP. 29-48 - ESTUDIOS I ISSN 2312-7562

UNIVERSIDAD NACIONAL DE INGENIERÍ, LIMA

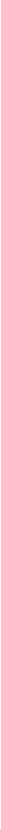

Figura 15. Boceto del proyecto de reconstrucción del lado noreste elaborado por Cossi Salas

Fuente: Cuadernos de investigación del Archivo Tello: $N^{\circ}$ 8. Arqueología de Pachacamac: Restauración del Templo de la Luna (p. 39), por J. C. Tello, 2010, Lima, Perú: CEPREDIM - UNMSM.
4) Los resultados hasta ahora obtenidos.

Incluir el plan y cuál fue la función del Templo de la Luna. Para lo cual exponer:

1) El plan del edificio, haciendo una corta historia de los planos publicados anteriormente;

2) Señalar el nombre de los diferentes edificios, patios y corredores que integran el Templo de la Luna, a saber: cisternas, terrazas, pabellones, sus orientaciones, etc. (p. 218)

Tello fue crítico y enfático en sus indicaciones de dejar como testigo las evidencias de las etapas de ocupación desde su inicio hasta la versión final del edificio, como cuando este funcionaba durante todo el esplendor de la época inca. Sin embargo, decidió la eliminación de elementos que fueron producto de la ocupación colonial y trasgredían la integridad del edificio, para lo que acudió a comparaciones con otros edificios del periodo inca, como el caso del Cuzco. De esto queda evidencia en las afirmaciones de Huapaya: "Siempre recordándome la importancia de la reconstrucción y la mejor manera de presentarla, porque como se sabe, es el objetivo principal la exhibición de las distintas épocas" (2010, p. 37).

Y es que la unidad de estilo, tal como lo planteaba Viollet-le-Duc, buscaba alcanzar el estado completo e ideal del bien a restaurar, así como de las obras de arte; por lo tanto, todo aquello posterior o ajeno a su estado final, como agregados y/o añadiduras, debía ser retirado, pues representa una ruptura de las leyes del estilo. Tello, siguiendo esa lógica, retiró los elementos posteriores al uso original del edificio, que correspondían al periodo de la Conquista, una época de ruptura que significó la depredación y saqueo de todas las riquezas de Pachacamac.

\section{De los críticos y defensores de la restauración, una revisión de documentos}

De la misma manera que Viollet-le-Duc, Tello fue acusado de falsear la historia del monumento debido a sus actividades de restauración, por lo que tuvo que enfrentarse a una serie de críticas, algunas de ellas publicadas en el diario La Prensa el 24 de febrero de 1944, vertidas por personajes como el Dr. Honorio Delgado, quien 




en su artículo titulado "La Falsificación como Síntoma de una Cultura Descendente" escribe lo siguiente:

Esa visita me fue penosa por las dificultades que encontramos para penetrar en el recinto de las ruinas, a algunas de la cuales se nos impidió acercarnos; por el progresivo deterioro que advertí en los pocos restos que quedan de las pinturas murales; pero más que todo, a causa de la escandalosa obra de "reconstrucción" (!) que se está ejecutando en la parte tal vez más interesante de la antigua ciudad sagrada, donde hay que admirar bellos muros de piedra descubiertos hace poco tiempo. Sobre esas construcciones multicentenarias se estaba fabricando con adobes un edificio, de modo que en lugar de tener a la vista lo
Figura 16. Detalle interior de un recinto reconstruido elaborado por Cirilo Huapaya en 1944

Fuente: Cuadernos de investigación del Archivo Tello: $N^{\circ} 8$. Arqueología de Pachacamac: Restauración del Templo de la Luna (p. 184), por J. C. Tello, 2010 , Lima, Perú: Universidad Nacional Mayor de San Marcos. 
que queda del antiguo monumento; se le incluyen en paredes nuevas, con aditamento pegadizo, se cubre y soterra la base del conjunto. Esto es lo que pudimos ver desde cierta distancia, y habríamos creído equivocarnos si no nos lo hubiera confirmado el propio empleado que no impedía acercarnos. Puede imaginarse nuestro estupor antes esta obra, antes estos hechos, que revela los peligros a que se está expuesto el patrimonio histórico de Perú, las entidades responsables deben extremar su vigilancia; y las instituciones que cuentan entre sus tesoros sus reliquias del pasado, están en el deber urgente de preservarlo de toda posibilidad de pérdida o desnaturalización, si el mundo sigue (progresando) en esta dirección y lo sofisticado, llegara el día en que la única alternativa que quede será: o falso o dudoso. (Delgado, 1944, 24 de febrero, p. 5)

Frente a ello, Tello (2012) respondió, en el mismo diario el 28 de febrero de 1944, con el título "Artículo del Dr. Julio C. Tello contestando al Dr. Honorio Delgado". Luego de describir los objetivos de la excavación, la metodología y trabajos previos al proceso de restauración, concluyó lo siguiente:

El edificio de las Mamaconas, tal como lo encontraron los conquistadores, ha sido fielmente restaurado. Es un gran palacio construido con adobes, cuya magnitud e ignora todavía. Muchos muros arrancan de1 grupo descubierto y se ocultan bajo las enormes masas de basura, arena y ceniza. Este palacio, que contiene cuatro altas terrazas adornadas con series de grandes nichos y hornacinas, y con techos sostenidos por columnas, con amplios corredores y con cuatro pabellones superpuestos conteniendo en cada uno de ellos diversos compartimentos, y con cisternas y un amplio jardín semejante a las chinampas de Xochimilco, fue construido sobre las ruinas de otro de menores proporciones, pero más bellamente edificado y con piedras labradas traídas de lejos.

Las excavaciones han cuidado de preferencia poner al descubierto todos los muros sepultados, y estoy seguro, por los muchos cateas realizados, que dentro del área actual no existe ya una sola piedra labrada que no esté a la vista; el visitante puede darse cuenta exacta de inmediato de cómo fue el primitivo edificio de piedras de ryolita, de cómo fue derrumbado para formar una extensa plataforma, y de cómo sobre ésta se levantó el edificio de adobes de las Mamaconas.

Esta reconstrucción es el motivo de las amargas lamentaciones y censuras del Dr. Delgado. (p. 209)

Días después, nuevamente en el diario La Prensa, esta vez en su sección editorial, se hizo eco de la crítica del afamado psiquiatra peruano:

\section{Las obras de restauración en la ruinas de Pachacamac}

Hace algunos días publicó este este diario un notable artículo del Dr. Honorio Delgado, que llevaba el siguiente título "La falsificación como síntoma de una cultura descendente". Es insigne escritor y hombre de ciencias se refiere en él al debilitamiento del sentido auténtico en nuestra época, y al gusto generalizado por lo convencional, hechizo y artificioso, sin dignidad artística; tendencia más lamentable aún si se extiende a los dominios del pasado, para adulterar los documentos históricos o los restos arqueológicos que nos queda como testimonio de las antiguas civilizaciones. A este respecto del Dr. Delgado cita el caso de lo que sucede actualmente en las ruinas de Pachacamac, donde, según pudo comprobar en una visita hecha recientemente por él, se ha emprendido una "escandalosa obra de reconstrucción (!), que se está ejecutando, en la parte tal vez más interesante de la antigua ciudad sagrada, donde hay que admirar bellos muros de piedra descubiertos hace poco tiempo". Y agrega: "sobre esas construcciones multicentenarias se estaba fabricando con adobes un edificio, de modo que en lugar de poner a la vista lo que queda del antiguo monumento, se le incluye paredes nuevas y, con aditamento pegadizo, se cubre y soterra la base del conjunto. 
Observaciones de tal índole, hecha por una persona de tan alta autoridad intelectual como el Dr. Delgado tenía que causar impresión en el ánimo público. Posteriormente LA PRENSA, acogió una carta del Dr. Julio C. Tello renombrado arqueólogo que dirige los trabajos en Pachacamac, quien explica la restauración manifestando que, tras prólijas excavaciones en el impropiamente llamado convento de las Mamaconas - en cuyo curso descubrió que "la antigua ciudad tenía depósitos, o reservorios y campos cultivados o jardines dentro el área hoy desértica de las ruinas"- practicó un estudio cuidadoso del terreno formados por los escombros de muros y techos, verificando todos los detalles de las hornacinas, de los nichos, de los restos de pintura y, en suma del largo proceso tecnológico de la edificación. Sobre la base de estos estudios se ha procedido a restaurar fielmente el palacio de las Mamaconas, dejándose deliberadamente en casa sitio, en cada nicho, y en cada esquina una muestra de la vieja construcción, como prueba de la limpieza y honradez de trabajo que se realiza.

Sobre esta materia no pueden opinar los lejos en aquello que se refiere a las particularidades de la ciencia arqueológica, pero sí en las relaciones con el concepto de la verdad histórica, con el respeto a los testimonios y huellas del pretérito; cuestión que -según apunta el Dr. Delgado-, es propia de toda persona culta, y no exclusivamente de los especialistas. En principio, una obra de restauración sobre las mismas ruinas es muy objetable y peligrosa, y, en todo caso solo podría justificarse excepcionalmente, cuando consta sin lugar a dudas que no queda ninguna posibilidad de mayores estudios, cuando los hechos para servir de fundamento a esos trabajos han sido presentados, expuestos a plana luz, debatidos por todos los hombres competentes y minuciosamente comprobados, $y$, en suma, cuando la reconstrucción es exigida por una verdadera necesidad, y con miras a un conocimiento más cabal y exacto de Pachacamac.

Esas condiciones no concurren en el caso de Pachacamac, pues se ha emprendido las labores de restauración sin que antes hubiese anunciado nada, sin que se demostraran la razón ni el fundamento que se tiene para hacerlas. La gran versación y capacidad de quien las ha proyectado y las dirige no están en tela de juicio; pero esa circunstancia no basta, pues nadie está libre de errar, y todo lo que se refiere al patrimonio histórico del Perú de ser considerado con la mayor atención y la más extrema prolijidad.

En nuestro concepto, del Ministerio del Ramo debe pedir una amplia exposición acerca de este asunto-, con los respectivos informes del Patronato de Arqueología - y llamar a consejo a todos los hombres de ciencia que pueden pronunciarse con plena autoridad sobre la restauración que se ejecuta en Pachacamac. (1944, 3 de marzo)

Si bien la discusión habría concluido con ese episodio, décadas después, entre los documentos pertenecientes a Albert Giesecke, se halló una carta inédita de Samuel Lotroph ${ }^{2}$, quien fuera gran amigo y colaborador del intelectual huarochirano. En este documento, Lotroph hace una aclaración destinada al diario La Prensa, la cual no fue publicada, donde expone claramente las ideas y quizás los presupuestos en los que se sustenta las actividades de conservación practicadas en el Acllawasi:

LA PRENSA NO LO PUBLICÓ - CARTA DEL SR. SAMUEL K/LOTHROP SOBRE LOS TRABAJOS DE RESTAURACION DEL TEMPLO DE LA LUNA (sic)

4. Marzo, 1944

Señor Director de "La Prensa"

Ciudad

2. Recuperado del Archivo Albert Giesecke 
Muy señor mío:

Molesto su atención para que se digne publicar la expresión de mi sorpresa después de leer el artículo del Dr. Honorio Delgado titulado "la falsificación como Síntoma de una cultura descendente" y el Editorial de "La Prensa" del 3 de marzo, el primero poniendo en duda la integridad moral y la capacidad de un peruano de fama mundial, y criticando las obras arqueológicas de Pachacamac, y el segundo llamando a consejo a todos los hombres de ciencia que puedan pronunciarse con plena autoridad sobre las restauraciones que se ejecutan en Pachacamac.

Según entiendo el Dr. Delgado, eminente médico psiquiatra - visito hace días las ruinas de Pachacamac, donde vio las restauraciones y excavaciones desde "cierta distancia" (más de doscientos metros), observando que era "escandalosa tales restauraciones" y que habría temido equivocarse si no lo hubiera confirmado el propio empleado que le impidió acercarse a ellas.

El buen Doctor sino tiene anteojos personales debe tener anteojos muy especiales para averiguar los hechos de tal distancia.

El científico está vedado de hacer diagnósticos a la distancia y mucho menos de servirse como base de sus afirmaciones de la mera información suministrada por un peón.

Para el Doctor Delgado la obra de reconstrucción en Pachacamac es una falsificación. Refiriéndome a restauraciones en general durante el siglo pasado y más, las naciones cultas han conservado sus monumentos históricos y a veces los han restaurado. El trabajo en Francia, por ejemplo, empezado por Viollet-le duc- dio como resultado, la restauración de gran número de chateaux e iglesias y condujo a obras similares en otros países de Europa. En el Nuevo Mundo; las reconstrucciones de edificios precolombinos ya terminados en Mexico (Teotihuacán, Kochikalko, Mitla, Monte Alban, Uxmal, Chizen Itzá etc) en Guatemala (Quirigué, Zaculen) y en Honduras (Copán) son conocidas de toda persona culta. No es cosa extraña pues que el concepto de reconstruir y conservar edificios antiguos exista en el Perú.

La cuestión de restaurar o no un palacio en Pachacamac no fue decidida únicamente por los arqueólogos técnicos. Tratándose de un asunto público, de carácter nacional e histórico, el trabajo se inició y desenvolvió según informe fidedignos, después de muchas consultas hechas por el Dr. Tello con los arqueólogos Nacionales y extranjeros y como resultado de la opinión de muchas personas, con el conocimiento y aprobación del Patronato Nacional de Arqueología.

Es técnica la manera de realizar los trabajos en Pachacamac, El Dr. Tello dice que la reconstrucción se ha hecho con limpieza y honradez; a esto yo añado, con inteligencia y sabiduría. La reconstrucción se basa primeramente en los hechos verificados por las excavaciones; y además representa todo un conjunto de opiniones de colegas arqueólogos, de ingenieros y arquitectos, unido a un estudio escrupuloso de todos los documentos históricos disponibles ef.

Durante las décadas posteriores, la restauración en el Acllawasi ha sido criticada por arqueólogos peruanos y extranjeros debido a la magnitud de la intervención (Burger, 2009); se ha acusado tanto al autor como a la obra de ser falsa o exclusivamente interpretativa. Sin embargo, las acciones de Tello respondieron tanto a su agenda personal como a su contexto político y social (Marcone, 2010). Además, de no haber llevado a cabo esta empresa, los edificios arqueológicos en Pachacamac hubieran sucumbido ante la presencia de las haciendas y la expansión de sus tierras de cultivo alrededor de las ruinas, así como debido a la intensificación de las visitas turísticas a inicios la década de la década de 1940. Tello, como lo hiciera su antecesor, Albert Giesecke, dio inicio al proceso de conservación de los sitios arqueológicos en el Santuario de Pachacamac. 


\section{Conclusiones preliminares y perspectivas de estudio}

Si bien Julio C. Tello, en sus obras y escritos publicados, no hace mención de los principios de restauración planteados por Viollet-le-Duc, es posible observar que en la restauración del Acllawasi existe un claro testimonio de su aplicación durante los trabajos de intervención, donde se sintetiza el conocimiento histórico del edificio y el exhaustivo conocimiento de las técnicas de construcción, lo cual tuvo como objetivo darle un uso más preciso al edificio en términos de su trayectoria histórica, a la par que plantear un análisis crítico de su accionar meditando, discerniendo y consultando con especialistas de diversos campos, en todo momento, sobre los procedimientos de restauración desde la misma gesta de la idea, pasando por su puesta en marcha, hasta su culminación.

Se trató de una intervención a gran escala, que fue defendida de las críticas de forma muy clara y precisa, como parte de un plan de trabajo exhaustivo y metódico que décadas después aún genera debate. En suma cuenta, la restauración del Acllawasi respondió al contexto ideológico, social, político y discursivo en el que vivió Tello.

Las líneas del presente artículo llevan a reflexionar sobre la magnitud de dicha intervención, realizada con elementos que hasta el momento se desconocían o que aún no eran públicos. Queda aún mucho por seguir estudiando respecto de esta etapa histórica de la conservación de los monumentos arqueológicos, sobre todo en el caso específico del Santuario de Pachacamac, con énfasis en el Acllawasi. Temas como la historia del edificio en cuanto a aquellas ocupaciones posteriores, como la colonial, los materiales recuperados y su análisis, aportarían mucho a un conocimiento más profundo de la historia del edificio.

Finalmente, queda pendiente el estudio de los materiales y las técnicas de restauración empleados, a fin de entender el estado actual de dicha intervención, lo que permitirá una mejor planificación para intervenciones futuras.

\section{Referencias}

Barrionuevo, M. (2007). Inventario de los sitios arqueológicos del distrito de Lurín: Mapa arqueológico. Lima, Perú: s/Ed.

Bueno, A. (2012). Introito. En J. C. Tello, Cuadernos de investigación del Archivo Tello: $N^{\circ} 10$. Arqueología e Historia de Pachacamac (pp. 9-26). Lima, Perú: Universidad Nacional Mayor de San Marcos.

Burger, R. L. (2009). The life and writings of Julio C. Tello. American's first indigenous archaeologist. lowa City: University of lowa Press.

Delgado, H, (1944, 24 de febrero). La Falsificación como Síntoma de una Cultura Descendente. La Prensa, p. 5. Lima, Perú.

Gonzáles-Varas, I. (2006). Conservación de bienes culturales. Teoría, historia, principios y normas (5ta ed.). Madrid, España: Cátedra.

Las obras de restauración en la ruinas de Pachacamac. (3 de marzo de 1944), La Prensa, p. 7. Lima, Perú.

Marcone, G. (2010). Más incas que los incas. Mirando la obra de Tello en su contexto intelectual. En Tello, J.C., Cuadernos de investigación del Archivo Tello: $N^{\circ}$ 8. Arqueología de Pachacamac: Restauración del Templo de la Luna, 1942-1944 (pp. 11-15). Lima, Perú: Universidad Nacional Mayor de San Marcos.

Matsumoto, G. (2005). Pachacamac GIS project: A practical application of geographic information systems and remote sensing techniques in andean archaeology (Tesis de maestría sin publicar). University at Carbondale, Southern Illinois.

Rowe, J. H. (1946). Julio C. Tello. Boletín de Arqueología, 2(3), 291-292. Bogotá, Colombia: Instituto Colombiano de Antropología e Historia. 
devenir Vol. 4, N7, ENERO- JUNIO 2017, PP. 29-48 - ESTUDIOS I ISSN 2312-7562

UNIVERSIDAD NACIONAL DE INGENIERÍA, LIMA

Rubio, M. (2007). Albert Anthony Giesecke Parthymueller. El más peruano de los norteamericanos. Lima, Perú: Nova Print.

Tello, J. C. (2009). Cuadernos de investigación del Archivo Tello: N 6. Arqueología de Pachacamac: Excavaciones en el Templo de la Luna y Cuarteles, 1940-1941. Lima, Perú: CEPREDIM - UNMSM.

Tello, J. C. (2010). Cuadernos de investigación del Archivo Tello: N 8. Arqueología de Pachacamac: Restauración del Templo de la Luna, 1942-1944. Lima, Perú: CEPREDIM - UNMSM.

Tello, J. C. (2012). Cuadernos de investigación del Archivo Tello: N 10. Arqueología e Historia de Pachacamac. Lima, Perú: CEPREDIM - UNMSM.

Wethered, C. (1875). On restoration. By E. Viollet-le-Duc and A notices of his Works In conection whith the historical monuments of France. Londres, Reino Unido: Sampson Low, Marston, Low and Searce. 